\title{
Hábeas Corpus: \\ contribuciones a la causa del estado de derecho
}

\author{
Habeas Corpus: \\ contributions to the rule of law's cause.
}

Norma I. Bouyssou

Profesora Adjunta Regular, Departamento de derecho penal y procesal penal, UBA.

Doctoranda, U. de Sevilla.

Fernando M. Machado Pelloni

Abogado, doctor en ciencias penales, USAL. Posdoctorando PUCRS, Porto Alegre

RESUMEN: La garantía del hábeas corpus despliega, con total humildad, razones para la permanente expansión de la libertad o bien para su contínuo resguardo. Su bajo perfil, sin embargo, es confundido con indiferencia en orden a su compromiso con la causa de la ciencia del derecho; ello se explica, por un lado, debido a la generalizada creencia que su reconocimiento expreso como derecho positivo -en los más altos niveles normativos-, es anticuerpo suficiente para puestas en peligro o atentados directos contra la autonomía personal a manos del Estado y, por el otro, lógicamente anclado en el predio precedente, en una suerte de desubicación contemporánea frente a un punto de partida de contención teorético (y en desuso del abuso) del poder político, al que no obstante se le exigen soluciones con mayor intervención fáctica (y menos frenos) en las relaciones sociales, aunque necesariamente adecuadas al orden anterior. Corresponde exponer la disconformidad con los pies en claves propias a la ciencia jurídica, sin hacer a un lado lo pragmático, método dual que se aplicará sobre la excursión que sigue, a la que se invita.

Palabras-clave: Proceso penal; Estado de Derecho; Habeas Corpus. 
ABSTRACT: The guarantee of habeas corpus unfolds, with all humility, reasons for the persistent expansion of freedom or for its continuous reinforcement. Its low profile, however, has being confused with indifference by his commitment to the cause of the science of law; this is explained, on the one hand, due to the widespread belief that its express recognition as positive law -in the highest levels of law standards-is a sufficient solution to jeopardizing or direct attacks to the personal autonomy in hands of the state and, in the other hand, logically anchored in the preceding grounds, in a sort of contemporary dislocation in front of a theoretical point of contention (and in unused abuse) of political power, to which, however, is required solutions with more factual intervention (and less limitation) in social relations, though necessarily suitable to the previous order. It corresponds to expose the disagreement with his feet on own keys to the science of law, without putting aside the pragmatic dual method that will be applied on the tour that follows, to which we invite.

KeY-words: Criminal procedure; Rule of Law; Habeas Corpus.

\section{I.- INGRESO AL TEMA}

La garantía del hábeas corpus despliega, con total humildad, razones para la permanente expansión de la libertad o bien para su contínuo resguardo. Su bajo perfil, sin embargo, es confundido con indiferencia en orden a su compromiso con la causa de la ciencia del derecho; ello se explica, por un lado, debido a la generalizada creencia que su reconocimiento expreso como derecho positivo -en los más altos niveles normativos-, es anticuerpo suficiente para puestas en peligro o atentados directos contra la autonomía personal a manos del Estado y, por el otro, lógicamente anclado en el predio precedente, en una suerte de desubicación contemporánea frente a un punto de partida de contención teorético (y en desuso del abuso) del poder político, al que no obstante se le exigen soluciones con mayor intervención fáctica ( $\mathrm{y}$ menos frenos) en las relaciones sociales, aunque 
necesariamente adecuadas al orden anterior. ${ }^{1}$ Corresponde exponer la disconformidad con los pies en claves propias a la ciencia jurídica, sin hacer a un lado lo pragmático, método dual que se aplicará sobre la excursión que sigue, a la que se invita.

\section{II.- Garantía Auditora del Estado de Derecho}

La idea seminal de nuestro seguro sobre la facultad personal de autodeterminación, desde una aproximación historicista, se concentraba en tres grandes áreas: a) un escudo de bloqueo o reparación contra el arresto, la prisión o cualquier otra forma de privación de libertad; b) la monitoreada custodia sobre los presupuestos esenciales del proceso legal debido hacia la aplicación de la ley penal sustantiva (sin la cual sus principios basales serían inocuos a la arbitrariedad) y, por último, c) el establecimiento de condiciones mínimas para personas legalmente afectadas en el goce de su derecho de circulación. Todas ellas remiten a la Magna Carta Libertatum (1215), al Habeas Corpus Act (1679) y al Bill of Rights (1689). ${ }^{2}$ A lo largo del tiempo, los conjuntos aludidos han tenido reconocimientos normativos en diferentes sistemas bajo modelos políticos distintivos; en un exploración interna a los Estados, desde la cumbre alcanzada por Leyes Fundamentales hasta pendientes o laderas infraconstitucionales -entre nosotros, art. $43 \mathrm{CN}$ (1994) pero años antes con la ley federal 23.098 (1984)- ; $^{3}$ mientras, en el circuito exterior

1 Cfr. Faria Costa, José De, "Habeas corpus (ou a análise de um longo e ininterrupto 'diálogo' entre o poder e a liberdade", de su Linhas de Direito Penal e Filosofia, Coimbra edit., Coimbra, 2005, p. 43ss.

2 Cfr. Kälin, W.-Künzli, J., The Law of International Human Rights Protection, Oxford U. Press, Oxford, 2010, p. 440ss.

3 La garantía penetró en toda América del Sur por influencia angloamericana, con las características propias a cada país; quizás con una excepción, si cabe proponerla así, en el caso de México y su cultural amparo; este último ha tenido con el reflotamiento de la Constitución de 1824 por la enmienda de 1847 la federalización de la garantía azteca, constitucionalizada en 1857 y revalidada después en el texto de 1917, que invariablemente ha permitido aún atacar decisiones judiciales, como retrata recientemente, Rozo Acuña, E., Il Costituzionalismo in vigore nei paesi 
pueden reconocérselos en compartimientos de hard-law, como en el circuito europeo de protección de los derechos humanos o del propio interamericano -arts. 6 CEDH. o 7, 8 y 25 CADH., respectivamente-, como en otro del tipo soft-law, tal y como conceptualmente encaja el instrumento de Naciones Unidas -art. 9.4 PIDCyP.-. ${ }^{4}$

Probablemente la mayor uniformidad al acercarnos al hábeas corpus la encontremos en su desconocimiento por el ejercicio de un poder sin control. Es, en realidad, un rechazo recíproco, puesto que la idea de una imposición cualquiera que fuere, falta de legitimidad y paralelamente fuera de toda legalidad, es contradictoria a una noción de libertad; a su turno, la limitación gubernamental derivada de tener por fin último el desarrollo humano -que no es el propio, sino el ajeno- se halla incómodo por la diversidad que implica y la pluralidad que representa, a la que vuelca toda su energía en doblegar y unificar cuando sigue un curso de deslegitimación e ilegalidad. En tal sentido, la garantía viene a ser la demanda del soberano al mandatario de un piso de racionalidad en la toma de medidas, privándole así, de la dominación

dell'America Latina, Giappichelli, Torino, 2012, p. 20ss, en especial la penetración comparativa con Europa en casos de Alemania, Austria, España y Portugal, p. 18 nota 1; sobre la variedad mexicana, Hernández Gómez, Isabel, "Los derechos humanos y la justicia constitucional", en Revista Dikaion-Lo Justo, Año 16, No 11, U. de la Sabana, p. 178. Brasil ha sido, entre todos ellos, el pionero con un registro que se retrotrae a 1830; cfr. García Belaunde, Domingo, "El Hábeas Corpus en América Latina (algunos problemas y algunas tendencias)”, en Revista de Estudios Políticos (Nueva Era), Núm. 97, julio-setiembre 1997, p. 109ss.

4 Vamos a agrupar como soft-law a los instrumentos elaborados en el marco de actuación de Naciones Unidas, que desde la Declaración de San Francisco de 1945 y hasta la Convención sobre Desaparición Forzadas de personas de 2006, existiendo siete tratados entre una y otra, que apenas cuentan con mecanismos de monitoreo, como los Pactos de Derechos Civiles y Políticos (PIDC.) y de Derechos Económicos, Sociales y Culturales (PDESC.) de 1966. Ese modesto esfuerzo, va contrastado con las protecciones regionales efectivas como hard-law y no limitado a la competencia contenciosa de los Tribunales, sino y en el caso europeo, a mecanismos de prevención paralelos a instancia del Consejo conformado por sus miembros. Así, De Schutter, Olivier, International Human Rights Law, Cambridge U. Press, Cambridge, 2010, p. 19ss. 
por la revelación o la fuerza, lo cual es bastante más que la justificación que extrae el que toma ventaja sobre aquél desaventajado. ${ }^{5}$ Los vectores opuestos, como el día de la noche, se evidencian en las críticas mutuas entre Laski y Schmitt. Para el primero, la autoridad que encare una tarea de gobierno debe atender a la máxima satisfacción de sus miembros, de ahí que tenga contenciones estatales -antes constitucionales, hoy además de hard-law- cuando no haga nada parecido y de ahí que una cosa -funcionario público, mandatario del soberano- y la otra -Estado- no se deban identificar; ${ }^{6}$ para el segundo, a contramano, aquello no puede generar la unidad política básica como para la sobrevivencia, ello así porque las asociaciones se repelerían entre sí y lejos estarían de una comunidad organizada, la cual no puede dejar a sus integrantes la libre identificación de sus peligros, reinventándose un (neo)Leviatán con capacidad de jus belli ante sus enemigos. ${ }^{7}$ Como somos prisioneros de la experiencia, vamos a acordar con el autor inglés. Sin la mínima pretensión de ser exhaustivos, la desaparición de la autodeterminación y la de su seguro, es una constante en las interrupciones al imperio de las Leyes

5 Eso supone el government of Laws and not of men, que traspasó con las colonias inglesas a suelo americano; el que más tarde sentará las bases del Estado Social y Democrático de Derecho, del que se comenzará a hablar en el continente europeo a partir del siglo XIX. Véase la contribución reflexiva de García de Enterría, E., La Lengua de los Derechos, Alianza ed., Madrid, 1999, p. 145ss. Otro tipo de concepciones de la soberanía, le dirá Holmes a Laski, no versa sobre el derecho sino sobre la siempre presente imposición de lo fáctico, en donde la conveniencia se vuelve dogmática. Así la carta de febrero 1 de 1919, The essential Holmes, ed. Posner, R., Chicago U. Press, Chicago, 1992, p. 265. Estas ideas alguna vez se plasmaron en sentencias de la Corte Suprema: “...la falta de causa lícita existe siempre que el objeto perseguido por un sector o conjunto de personas consista en aniquilar la libertad e instalar la dictadura, arrasando las instituciones que reposan en el respeto sustancial de los derechos humanos" (énfasis propio, Fallos: 278-287 y citas).

6 Cfr. Laski, Harold, El Estado en la teoría y en la práctica (trad. Herrero, V.), Reus, Madrid, 2008, p. 26ss.

7 Cfr. Schmitt, Carl, "Il conetto del politico", en Posizioni e conetti. In lotta con Weimar-Ginevra-Versailles 1923-1939 ( a cura di Caracciolo, A.), Giuffré, Milano, 2007, p. 105ss. 
Mayores de Argentina, ${ }^{8}$ Brasil $^{9}$ y Chile $^{10}$ en donde se ahogaron los derechos fundamentales; pero también nos muestra que aunque necesario, per se es insuficiente ante la disminución de la cualidad democrática, sea en Colombia ${ }^{11}$ o Perú. ${ }^{12}$

8 Un compendio descriptivo del caso argentino lo da la propia Corte durante el último gobierno de facto. Mientras el Tribunal señalaba que excedía la competencia de la magistratura el análisis de las causas o que no le correspondía valorar la contradicción de las instituciones con la causa de la libertad, dijo además que exhortaba a la función ejecutiva en el poder (que era por otra parte la que se sustraía de la legalidad y la judicialidad de los actos de gobierno) a que adoptara las medidas necesarias para que la función jurisdiccional pudiera volverse efectiva, concretamente, en la obtención de respuestas frente a la interposición del hábeas corpus. In extenso, véase Fallos: 300:1282.

9 Brasil sufrió por un largo período a los gobiernos dictatoriales, con mayor o menor represión armada, entre 1964 -el advenimiento de la Quinta República- y 1985. Eran moneda común atos institucionais que suspendían la dimensión protectora de ese escudero de la libertad como es el hábeas corpus, mientras expropiaban la soberanía popular y la colocaban en las ensanchadas atribuciones de quienes ejercían el poder de facto. En tal sentido es meritoria de recordar el Acta $\mathrm{N}^{\circ} 5$ de diciembre 13 de 1968 con la firma del presidente Artur da Costa e Silva, que junto al Estatuto de Seguridad Nacional y el Servicio Nacional de Información, autorizado por la Constitución de 1967 -violada como es obvio, aunque era represiva-, dieron un marco pseudo-normativo a la arbitrariedad. Véase, Rozo Acuña, E., Il Costituzionalismo in vigore nei paesi dell'America Latina, op. cit., p. 615ss.

Durante la toma y ejercicio del poder (militar) de Augusto Pinochet, pocas veces el hábeas corpus fue admitido; en este sentido lo recuerda Nogueira Alcalá, H., "El hábeas corpus o recurso de Amparo en Chile", en Revista de Estudios Políticos (Nueva Era), Núm. 102, octubre-diciembre 1998, p. 200.

11 Para enfrentar luchas armadas o poner coto al delito, con la peor rebaja de la moral estatal, ampliar en Herrera Pérez, Jairo E., "Caras nuevas y viejas y problemas en Iberoamérica del Hábeas Corpus", en Estudios Constitucionales, $\mathrm{N}^{\circ}$ 2, U. de Talca, 2006, p. 19ss, especialmente 28 y 29.

El gobierno peruano, que atravesó problemáticas cualitativas similares al de Colombia aunque pareciera que en otra cuantificación por la perdurabilidad, también militarizó la intervención estatal contra el fenómeno bajo la presidencia de Alan García y fue mucho más allá bajo la de Alberto Fujimori. En principio, análogo al mandatario argentino Eduardo Duhalde en materia de amparo frente a la (saqueada) propiedad privada 
En cierta forma, el hábeas corpus señala que el relativismo en el pentagrama es, paradoja mediante, la única y constante nota admisible -mucho más en tiranías ad origine pero no necesariamente menos en las ad regimine- para la defensa y también para la promoción de la libertad. Es decir, supondrá una movilidad estatal hacia la libertad, será absorbido en el derecho positivo y adaptado tantas veces como ese fin caracterológico al Estado de Derecho se lo exija, mostrándose, a su vez, intolerante ante una generalizada ausencia de tolerancia. ${ }^{13}$ Sin embargo, en lo que a la garantía concierne, la propia dinámica política de poderes incontenibles la inmovilizan en la estructura ósea estatal -o debe perpetuamente intentarlo- cuanto valor sustantivo aunque de transmisión formal, como un continente indisponible y definitivo de la conquista o de la supervivencia democrática y, también, como un im-

-art. 12 dec. de necesidad y urgencia 214/2002- con los decretos legislativos $\mathrm{N}^{\circ} 824$ y 895 en donde, en ese orden, quienes estuvieren imputados de narcotráfico quedaban excluídos del seguro de la libertad y los de terrorismo, debían concurrir por la garantía ante la judicatura militar; más tarde con el decreto legislativo $\mathrm{N}^{\circ} 900$, persiguió limitar, la interposición de las acciones por desapariciones y encarcelamientos arbitrarios ante salas especiales de derecho público. De ahí que se suscribiera: "Nunca antes como ahora el ejercicio del poder político gubernamental ha llegado a amenazar y a cuestionar la propia jurisdicción constitucional, como ha quedado evidenciado en los últimos años... Dicho en otras palabras, muestra los límites del control constitucional del frágil Estado de Derecho peruano, administrado por las mismas autoridades que en 1992 no tuvieron reparo en quebrantar la institucionalidad constitucional, clausurando entre otros organismos constitucionales al Tribunal de Garantías Constitucionales, por considerar que sus resoluciones no eran conformes con el proyecto político y económico promovido por el gobierno y los poderes fácticos"; véase, Landa, C. "Protección de los derechos fundamentales a través del Tribunal Constitucional y la Corte Interamericana” (ponencia del Congreso Menschenrechte und Grundrechte, Freie Universität Berlin, junio 3-5 de 1998, reproducida en Pensamiento Constitucional, Pontificia Universidad Católica del Perú, Año V N 5, Lima, nov. 1998, p. 76ss y 79 en lo puntual; más ampliamente, informe final presentado al Honorable Congreso del Perú por la Comisión Investigadora, Lima, junio 15 de 2002.

13 Sobre la importancia del entendimiento del relativismo en esta clave, Radbruch, Gustav,,Der Relativismus in der Rechtsphilosophie”, en Rechtsphilosophie III, C. F. Müller, Heidelberg, 1990, p. 17ss. 
perativo de la realidad jurídica, acaso como una de sus más esenciales doctrinas, algo así como la máxima de la decimonovena disposición de la Norma Fundamental alemana, cuya matriz kantiana defiende y repele -a modo de salvaguardia- agresiones al contenido esencial de los derechos humanos. ${ }^{14}$

En un punto, se trata de la penetración cultural de la preocupación por la subsistencia de la autonomía como valor, a razón de los embates desde todos los ángulos, y por múltiples ideologías, contra ella. ${ }^{15}$ Desconocerle como problema, es negar lo que subyace a la articulación de programas compatibles con la dignidad personal, la legalidad -sustantiva y adjetiva- ligada a la racionalidad estatal, la defensa contra las injerencias del poder - por fuera o por debajo de los límites consensuados con los mandantes- y la tutela jurisdiccional -con sus presupuestos, independencia, imparcialidad y con revisión- ${ }^{16}$

14 Sobre la imposición de una doctrina esencial, más allá del pensar del observador o de su volición, Kaufmann, Arthur,,Rechtsphilosophie, Rechtstheorie, Rechtsgomatik", en Einfübrung in die Rechtsphilosophie und Rechtstheorie der Gegenwart, C. F. Müller, 2011, p. 11ss y 61. El art. 19.2 GG. señala: "En ningún caso, un derecho fundamental puede ser lesionado en su contenido esencial" (In keinem Falle darf ein Grundrecht in seinem Wesensgehalt angetastet werden). Véase ut-infra, nuestro cierre.

15 La cultura, en este tópico, viene desde el rechazo a la violencia institucional. Sobre la importancia de esta en la justificación del derecho, Radbruch, G.,,Rechtsphilosophie”, en Rechtsphilosophie II, C. F. Müller, Heidelberg, 1993, p. 315ss; en sentido constitucional, Häberle, Peter, Die Verfassung des Pluralismus, Athenäum, Königstein, 1980, p. 55ss y 57, y reciente, respecto de la importancia de museos u otros bienes en la formación de la identidad cultural,,Die Erinnerungskultur im Verfassungsstaat”, Duncker \& Humblot, Berlin, 2011, p. 16ss. Ligado a lo que se trata, el de la Memoria, para el caso argentino, en lo que fuera la Escuela Mecánica de la Armada, o simple y fatalmente ESMA.

Son los presupuestos propios a la función política de la judicatura los que, a su vez, descartan su rendición a la política de identidad ideológica. Cfr. Faria Costa, José De, "Habeas corpus (ou a análise de um longo e ininterrupto 'diálogo' entre o poder e a liberdade", de su Linhas de Direito Penal e Filosofia, op. cit., p. 50; idéntico sentido le asignaba textualmente a la garantía, con mención del inventario por el que la judicatura no era un mandatario de la función ejecutiva, Sir Winston Churchill, "The sinews of 
Sirva lo anterior a modo de preludio en las agitadas aguas de la edad de los derechos. El registro oficial de la documentación de la garantía de la libertad y su contínuo perfeccionamiento a lo largo de la historia -van más de 798 años de conocimiento sobre su existencia, y ello porque puede que tenga todavía más tiempo de vida-, le sitúan como ingeniería - un canal acceso para la solución- en el pórtico del aparejo de los derechos fundamentales, es decir, en el mundo de lo judicialmente exigible. ${ }^{17}$ Los historiográfos más diversos, sin embargo, no vacilan en advertir que la transformación que experimentan aún aquellos más antiguos, no contraviene la esencia que les identificó en la matriz, sino que la potencia, amplificándola en una nueva variable, la que seguramente antes venía desautorizada o, sin más, se presentaba inimaginable. ${ }^{18}$ Ello explica como, a pesar de la subsistencia de alguna opinión condicionada al sostenimiento de la delimitación de origen y que confunde la senectud de lo que se cuida, por la preferencia y exclusividad acotada a restricciones y limitaciones del desplazamiento o a condiciones sobre la

peace”, en Winston Churchill. His complete speeches 1897-1963 (ed. Rodhes, R.), vol. VII, Chelsea House Publ., London, 1974, p. 7288ss.

17 Sobre el rastro reciente, Machado Pelloni, Fernando M., "Hábeas Corpus: 797-3”, en Derecho Procesal Constitucional, JA. número especial 2012-III, Sagüés, N. P.-coordinador, BsAs., p. 21ss.

18 Por ejemplo, sin perjuicio de lo que se desarrollará ut-infra en el texto sobre política criminal, se acierta con la invocación de la tortura desde un expositor del iuspositivismo: no cabe duda que la Declaración Universal de Derechos Humanos de 1948 es un paso fundamental hacia los valores que pueden encerrar aquellos, ahora su comprensión como naturales e invariables no se infiere, tampoco vía consenso, puesto que históricamente, se homologaba la violencia en la producción probatoria del juicio penal y, por fortuna, en la actualidad no; Bobbio, Norberto, El tiempo de los Derechos (trad. de Asis Roig, R.), Sistema, Madrid, 1991, p. 65. Otro jurista, pero de escuela opuesta, también acierta: tras los pasos de Edward Coke, se advierte que por el Habeas Corpus Act no se discute ningún derecho humano, sino uno fundamental, para ingleses y no para todas las personas, del que estaban excluidos extranjeros, mujeres y niños; de modo que no existió otrora, tal y como ahora lo conocemos. Véase, Oestreich, Gerhard, Die Idee der Menschenrechte in ihrer geschitlichen Entwickñung, Colloquim Verlag, Berlin, 1974, apartado 1.2 in extenso. 
legalidad de su impedimento, ${ }^{19}$ con rigor deóntico asistimos a una poderosa obstaculización de la arbitrariedad del poder político, mucho más allá de lo que resultó en origen. Esa movilidad del predicado conceptual alimenta la seguridad jurídica de la causa. Con un doble impacto, según la posición que nos identifica. Profundicemos.

Explica, in primis, que en el curso vital de un Estado, nuestro seguro tenga - ¡y deba tener!- coberturas diferenciadas. Ello es así, en la medida que la libertad cambie de problemas y no como, al contrario de lo que pueda intuirse, resulta que deje de tenerlos. En un zona condivisa tanto para gobiernos autoritarios como para los democráticos, la hipótesis básica del hábeas corpus es que, como derecho, abra un proceso judicial urgente por el que se puedan discutir las bases de una detención tachada como ilegal; ${ }^{20}$ en cualquier caso la real distancia entre uno y otro será la enorme dificultad de iniciarlo -en lugar de probarlo- para el primero; pero hay que describir la merma a la hora de alcanzar una decisión -ya no de buscarla- para el segundo. Aunque sea empíricamente refutable, persiste la creencia que los atentados o los peligros para la libertad se ciernen apenas cuando un país está al margen de su Ley Mayor, cuando todo el sentido se orienta, justamente tal y como lo señala Faria Costa, a que la inclusión en la norma constitucional de aquél -o bien su adhesión a un sistema de hard-law- persigue excluir también arbitrariedades en el perfeccionamiento institucional de la calidad democrática. ${ }^{21}$ De lo anterior se sigue, en el segmento temporal contemporáneo, que la garantía, por la superioridad que un modelo estatal presupone ante el otro, cuenta - iy ello porque debe hacerlo!con muchas más pretensiones respecto de los derechos fundamentales

${ }_{19}$ Como atenuación hay que atender que la libertad puede ser derecho preferido frente a DESC desatendidos, por obedecer a factores culturales propios al Reino Unido. Remito, no obstante, a la importante contribución de Trechsel, Stefan, Human Rights in Criminal Proceedings, Oxford U. Press, Oxford, 2005, p. 463ss.

20 Cfr. ECHR, "Brogan and Others v. United Kingdom", app. 11209/84/11234/ 84/11266/84/11386/85, rta. 29/11/1988, pars. 32, 40 y 58.

${ }^{21}$ Cfr. Faria Costa, José De, "Habeas corpus (ou a análise de um longo e ininterrupto 'diálogo' entre o poder e a liberdade”, de su Linhas de Direito Penal e Filosofia, op. cit., p. 51. 
de libertad. Dicho en abstracto, se trata de una de las dos variantes del principio de proporcionalidad: i) regularmente -estricta proporción directa-, expandir la cualidad y la cantidad de la materia protegida inherente a la regla democrática ${ }^{22}$ y ii) irregularmente-proporción inversa-, ante la aplicación de cláusulas de emergencia o excepción -inapropiadas por la delgada línea en la que se confía dividir y separar el imperio de la ley, de su abrogación-, mayor severidad en la búsqueda de racionalidad ante decisiones privativas o limitativas de los atributos inherentes a toda persona, con pretextos fundamentados en casos extraordinarios. ${ }^{23}$

22 Con razón, entonces, puede articularse un hábeas corpus para que el área de auxilios sanitarios de la Unidad $\mathrm{N}^{\circ} 11$ cita en Baradero, provincia de Buenos Aires, cuente con móvil, medicación -entiéndase no vencida, más la necesaria según posología para pacientes internos $\mathrm{HIV+-}$, calefacción, gas, agua potable y servicios, y con facultativos; así la presentación de la defensora de ejecución penal del departamento judicial de San Nicolás, junio de 2013. Situación deficitaria que ante exigencias de la dignidad personal, no se puede -¡ni debe!- sustraer la autoridad judicial federal -en la dimensión humanista que se opone a que razones de distribución vertical del poder son inoponibles a violaciones de derechos humanos-; p. ej. cuando en una unidad salteña y más allá de problemas presupuestarios -la magistratura no se hace cargo de evaluar si son autogenerados, por pésima gestión en la imputación de las finanzas públicas, tampoco si del vergonzoso estado de situación resulta relevancia típica-, los tribunales deben atender graves fallas en el reconocimiento y respeto de los derechos de las personas (incluso las) detenidas. Véase CFCP, Sala IV, in re "Secretario de Derechos Humanos de la provincia de Salta s/rec. de casación”, c. 603/2013, reg. 1284/13.4.

${ }^{23}$ Las decisiones que afectan el goce del derecho de libertad están sujetas al control judicial por la garantía constitucional, debiéndose guardar relación entre la declaración del estado de emergencia y la orden de arresto, para que sea convalidada, según doctrina de Fallos: 307: 2284 y respecto del art. 4.2 de la ley 23.098 (en aquella ocasión, el voto en disidencia recoge el problema de la proporcionalidad y propiciaba un revisión judicial más fuerte que la de la mayoría; soy de la opinión que esa minoría -similar a la de Fallos 243:504- debiera ser hoy opinión dominante, más tras la reforma de la CN.). Para mayor reflexión, Machado Pelloni, F. "Hábeas corpus: pasado, presente y futuro. Teoría y práctica”, en Estudios Constitucionales, Año $5 \mathrm{~N}^{\circ} 1$, U. de Talca, 2007, p. 31ss; y también Machado Pelloni, Fernando M., "Hábeas Corpus: 797-3", en Derecho Procesal Constitucional, op. cit., nota 11 en especial. Se destaca además la tendencia a revisar incluso los presupuestos 
In secundis, robustece el goce de los derechos fundamentales, por un conciente -o no- aporte a su indivisibilidad. En esta zona de navegación, las antiguas cartas diferenciaban según edades y distinguían, a grandes rasgos, aquellos de aguas seguras respecto de lo judicialmente decidible de otros de áreas inseguras, propio de lo no (tan) judiciable. La garantía viene, en clave de faro, a alejarnos del arrecife, para recordarnos que la libertad tiene -iy debe de ser!- preservada, además del poder estatal omnipotente, de una indefendible economia de exclusión y marginación. ${ }^{24}$ Esto, que no se refleja lo suficiente en decisiones judiciales altamente cuestionables en su correspondencia con el modelo del Estado social y democrático -tal y como se señaló recién-, hace parte de un camino de transito gradual e irreversible que, no obstante, denuncia a su vez la imposibilidad cultural de desentenderse de la misión comprometida y posibilista de la configuración de una nueva realidad de las personas en relación con sus derechos esenciales. ${ }^{25}$ En efecto, el

de la excepción, antes cuestión política; Midón, Mario A., "E1 hábeas corpus durante el Estado de sitio y frente a la desaparición forzada de personas", en Tratado de Derecho Procesal Constitucional (Manili, P. director), T. I., La Ley, 2010, p. 683ss.

${ }^{24}$ Porque esta experiencia ya ocurrió con la revolución industrial, como claramente explicita Oestreich, Gerhard, Die Idee der Menschenrechte in ihrer geschitlichen Entwickñung, op. cit., ap. 5.

25 Uno a favor, es el caso del Expte. 51817 "Dres. Patricio N. Sabadini y Carlos M. Amad -fiscales- s/interponen acción de hábeas corpus correctivo a favor de Daniel Eduardo Soria”, 14-5-2013, sent. Interlocutoria $N^{\circ} 23 \mathrm{~T}_{\mathrm{VII}} \mathrm{F}^{\circ}$ 84/85 año 2013, de la CFCC de Resistencia, que revoca -cuando se le eleva el proceso- el desentendimiento de la habitabilidad y de los cuidados de la salud de parte del juez del hábeas corpus, para privilegiar la intervención de su colega de ejecución; el a quem recomienda celeridad en el tramite y atención al problema constitucional e iusfundamental, que implícitamente no bastaría con un caritativo oficio -como Pilatos- a la autoridad ejecutiva, para que tenga a bien acompañar al detenido a un hospital extramuros, hasta que el magistrado competente se concentre en resolverle el tema. Otro en contra, es el Expte. 6071 “I. F.G.S. s/Ley 23098”, 15-3-2012, T. 74 F. 114, Sala I CFCC de La Plata, en el que el tribunal de apelaciones se sustrae de analizar, por la garantía, una manifiesta lesión al derecho de trabajar intramuros; asunto emparentado con el trato digno (no arbitrario) y el derecho alimentario (proprio -pues la comida provista en la penitenciaría ningún 
proceso histórico impide el progreso de concepciones brutalmente represivas, ${ }^{26}$ al tiempo que persigue sintetizar por la intervención penal estatal necesaria su propia ausencia, tan caracterológica a la abrumadora dominación del capitalismo, en la medida que su puerto de refugio es la integración social. ${ }^{27}$

Para que se entienda, lejos de confirmar que la merma de la libertad es el común destino de las personas atascadas en las carencias de todo signo, la proposición es -o cuanto menos debiera ser- expandir las opciones para la autonomía en todos los frentes, lo que afectará la reducción de opciones -para muchos podría implicar sin más un determinismo- que potencie el delito. ${ }^{28}$ Por eso la función de tutela talla -y está constreñida a hacerlo- en la ecología humana marcada por las geografías

magistrado del triunvirato la comería- y del núcleo primario -asistencia económica como ayuda, máxime con una reciente paternidad-), todo tratado por la ley de ejecución 24660 -arts. 106/7- que reglamenta el art. $18 \mathrm{CN}$ in fine. Si bien reconoce la fundamentación del reclamo, en todos los niveles normativos, no puede conectar la mortificación psicológica a la que se expone al actor -acaso crueldad-, cuando se le recorta la carga laboral al tiempo que nace su hija e indagar si lo que denuncia tiene verificación; a pesar de ello, envía dos señales: i) al posible lesionado, para que distinga que esto -¿quizás otra discriminación irrazonable no?- debe esperar en la bolsa del juez de ejecución -aunque el a quo solicitó por oficio a la administración que subsane la restricción, ¡más no se puede pedir!- y ii) al posible autoritario, para que advierta que el control formal o aparente, se sostiene (apenas) como para, reunidos quien sabe que otros extremos fácticos, convertirse en uno material o real. El señorío de la administración sobre el interno se puede volver en extremo arbitrario, como cuando se dificulta el traslado para estimular la integración familiar, sin causa -al menos expuesta en el trámite procesal-; así el hábeas corpus resuelto en CFCP, Sala IV, "Lefipán, Walter Roberto s/ recurso de casación” c. 592-13, reg. 1397-13, rta. 9-08-2013.

${ }^{26}$ Cfr. Moccia, Sergio, El derecho penal entre ser y valor. Función de la pena y sistemática teleológica (il diritto penale tra essere e valore. Funzione della pena e sistematica teleologica, trad. Bonnano, A.), BdeF, Montevideo-BsAs, 2008 , p. 5.

27 Se puede ampliar en Mantovani, Ferrando, Il problema della criminalitá, Cedam, Padova, 1984, p. 191ss.

28 Cfr. Mantovani, Ferrando, Il problema della criminalitá, op. cit., p. 187ss. y 199. 
deficitarias en donde puede haber más presión punitiva, arbitraria e indiscriminada; y por eso tiene que hacerse cargo de probar la indivisibilidad de atributos básicos: es inadmisible que exista un compromiso judicialmente revisable en el plano de una prevención especial supuestamente necesaria revelada en la salud, el empleo y la educación del derecho civil de un interno y que pueda diferírsela cuanto presuntamente facultativa e insatisfactoria en la arquitectura de la política pública del derecho económico, social y cultural de la persona en libertad. ${ }^{29}$

29 Sobre este tema podría decirse mucho más, que por razones de tiempo y espacio en nuestra invitación, diferimos para otro momento. No obstante, se adelanta cuanto se comparte de un hábeas corpus capaz de prestar colaboración hacia una configuración política integradora de un Estado social y democrático de derecho, de arraigo en la legalidad material; Mendes, Antonio Alfredo, Habeas corpus e ciudadania, Quid Juris, Lisboa, 2008, p. 88 ss. Además de valorárselo como un testimonio de la igualdad en la concepción de los derechos fundamentales, que, entonces, no tienen una garantía diferenciada en cuanto exigibilidad, según sean civiles o económicos, sociales y culturales; para otros aportes ya no relacionados con nuestro tema, se puede acudir a Pisarello, Gerardo, Los derechos sociales y sus garantías, Trotta, Madrid, 2007, p. 79ss. (y antes su introducción).

Del lado de las decisiones judiciales, la acción n. 134 del juzgado departamental de Lomas de Zamora -setiembre 11 de 2013- debe rescatarse, en la medida que traba el flujo de seres humanos que excedía ampliamente el cupo del establecimiento dependiente del Estado local bonaerense; ello amén de la inhabitalidad, comprometía la integridad física de los allí alojados como así también la educación, la salud y la integración familiar. Por estar privados legítimamente de la libertad, los derechos comprometidos no podrían, por aquella causa, dejar de ser amparados. La densidad es una preocupación patagónica, habida cuenta que la unidad de encausados también tenía exceso de población, lesionándose la recreación indispensable, de salir al patio y recibir luz solar, lo cual fue recuperado como derecho; expte. 14-5-2012, "Morales, Ignacio Alejandro s/hábeas corpus", Sala B de la Cámara Criminal de Viedma, rta. 26-01-2012.

A los anteriores se le suma la expansión disciplinaria, de incremento al ya impuesto factor penal, en forma casi automática en determinados centros de la provincia de Buenos Aires - por lo que traspasa los cimientos del procedimiento ejecutivo correspondiente-, lo cual fue abortado también por la tutela garantística: el aislamiento deteriora la salud física y psíquica, por lo que debe estar sometido a control y debe ser proporcional pero fundamnetalmente 


\section{III.- GARANTÍA DIRIMENTE dE LA POLÍTICA CRIMINAL}

La indispensable intervención estatal para asegurar derechos fundamentales, lo cual hace a la intervención penal necesaria, debe balancearse con la probibición de exceso en la regulación y en la injerencia sobre aquellos. Brevemente, que la estrategia estatal resulte coherente y, entonces, que para tutelar, no se lesione la dignidad personal. ${ }^{30}$

bumano, eje de los datos normativos internacionales de hard-law como de softlaw, como así también la Ley Mayor e incluso los reglamentos, reseñados en la resolución; así, c. 1339-13, "Daniel Surgen y Marcelo Vilanova. Hábeas Corpus colectivo", Cámara de Apelaciones y Garantías de Necochea, junio 27 de 2013, en especial el voto del juez Noel. Otro importante antecedente cuenta de la discusión sobre la defensa de intereses por delegados de la población carcelaria y ello por reuniones mensuales, representación por la que perseguían unirse para protegerse de la lesión de aquellos por los agentes y funcionarios penitenciarios; dos aspectos, en alguna medida ligados al interior, que es una suerte de intermediación, para evitar hábitos discriminatorios propios de una ecología humana de facto con las visitas, como la descomunal fuerza anónima -por personal sin identificación- aplicada a las requisas: el sumarísimo autorizó la representación e hizo lugar a las propuestas para racionalizar el caos en el que la administración envuelve a los familiares para concretar visitas y autorizar su ingreso con alimentos, en horario con prioridades según se trate de menores o personas muy mayores e higiene en las áreas y momentos de concretarlas; exhortó, además, a mejorar las telecomunicaciones. Así, c. 43806/12 "Alejandro Gutierrez y Claudio Orosman Castaño s/hábeas corpus", juzgado en lo Criminal de Instrucción $N^{\circ} 31$, Secretaría N ${ }^{\circ} 119$, rta. 4-12-2012. En idéntico sentido, el aseguramiento de condiciones dignas para la convivencia intramuros fue exigida judicialmente al Servicio Penitenciario Federal, cuando se ordenó la provisión de electricidad, calefacción, refrigeración, agua potable y mecanismos de prevención contra incendios, en la cárcel federal neuquina, que además denunciaba castigos de facto por vía disciplinaria y con los agentes de la requisa -que había llegado hasta causas penales contra sus cuadros-. No había discriminación razonable en el tratamiento de los internos y se había comprobado una problemática alimentaria y sanitaria que se ordenó subsanar; así c. 94/12 "Ministerio Público Fiscal s/recurso de hábeas corpus”, Juzgado Federal de Nequén, Secretaría N² 2, abril de 2013.

30 Ampliamente, Viganó, Francesco, "Obblighi convenzionali di tutela penale?”, en AAVV., La Convenzione europea dei diritti dell'uomo nell'ordinamento penale italiano (a cura di Manes, V.-Zagrebelsky, V.), Giuffré, Milano, 2011, p. 243ss; con matices, Feldens, Luciano, A Constituição Penal, Livraria 
Bajo los puntos cardinales anticipados, creemos que el hábeas corpus es una herramienta elemental y un punto de apoyo sólido para perseguir el fugaz equilibrio entre la acción debida y la abstención por igual obligada, para compensar la función del poder en acción, con la libertad inherente a los seres humanos. ${ }^{31}$ Es que si otro pilar del derecho es perseguir la seguridad en general desde la cognoscibilidad, ella también ocupa una plaza en particular en el tejido de las relaciones interpersonales, en especial cuando la limitación necesaria en la arena de los derechos humanos es aceptada por unos y traspasada, como abuso frente al cumplimiento de aquellos, por otros. La unión de los puntos en nuestra navegación indica que la certeza es una indiscutible propiedad de la ciencia jurídica y que importa en demasía, aunque no es menos que un medio para el posicionamiento de los valores que persiga a través de las normas. ${ }^{32}$ Dicho lo anterior, siempre hay un orden normativo propio a un Estado democrático, opuesto al de otro autoritario. ${ }^{33}$ Para preservar

Do Advogado ed., Porto Alegre RS, 2005, p. 69ss. Sobre una diferencia con el último, la tesis doctoral inédita, Machado Pelloni, Fernando M., Desobediencia \& delito, Parte I. Para agotar el asunto, Mantovani, Ferrando, Il problema della criminalitá, op. cit., última parte de la obra, p. 395ss.

31 Esta permanente contienda, entre poder y libertad, es una de las pulseadas más constantes e importantes del derecho público en el que tributa el ordenamiento penal. Si bien el capital cultural tributa al Estado social y democrático, y en ese punto puede ser un obstáculo a cambios, no puede perderse la atención sobre que aquella es producto de vivencias humanas concretas, que pueden, en suma, modificarse; así, Recasens Siches, Luis, Filosofía del Derecho, Porrúa, México DF., 2008, p. 97ss. Ello así, hay que procesar con cuidado las valoraciones subyacentes a las ideologías que condicionan la arquitectura de la respuesta en materia de política criminal; Moccia, Sergio, El derecho penal entre ser y valor..., op. cit., p. 8ss. La mutabilidad racional puede descansar en libertad, tolerancia y democracia -como exponía Radbruch (nota 13 ut-supra)- pero no es inexpugnable al germen autoritario; Kaufmann, Arthur, Kaufmann, Arthur,,Rechtsphilosophie, Rechtstheorie, Rechtsgomatik", en Einführung..., op. cit., p. 18.

32 Ampliamente, Recasens Siches, Luis, Filosofía del Derecho, op. cit., p. 220ss.

33 Se puede señalar que la baja incidencia del fenómeno delictivo entre los habitantes, tenga o pueda tener relación con el incremento de la criminalidad estatal; Mantovani, Ferrando, Il problema della criminalitá, op. cit., p. 191ss; o que más allá del aspecto cultural, aquél en propiedad no sea de conformi- 
a uno y prevenirse del otro, la garantía debe aprobar cualquier iniciativa reglamentaria respecto de la autodeterminación individual.

Señalado lo anterior, con premura hay que destacar que no puede esperarse del seguro constitucional que impide el progreso de una política estatal por exceso, que por igual la configure ante un déficit. Más allá de unas piedras basales, principios que optimicen la imaginación de reglas (o simple elucubración de las últimas, a instancias de algunos protagonistas de la política), aquella tarea supera su teleológica orientación. Es decir, no prescribirá como acabar con el delito (aunque algunos todavía no distingan el hecho punible de sus autores presuntos). Declarará la probibición de qué, cómo y cuándo la regulación amenaza, hiere o profundiza la agresión más allá del límite constitucional o convencional al derecho de libertad. ${ }^{34}$

Así los márgenes, no prospera -iy no debe hacerlo!- la politica criminal de facto. La intervención en el espacio público, donde más seguridad para los derechos básicos se demanda, se materializa en un complejo condominio, cruzado por distintas disciplinas, más las tributarias de la ciencia jurídica: las primeras condicionan la articulación de las segundas y en la medida que se sostenga una pretensión de compatibilidad regulatoria de conformidad al marco constitucional y convencional, por sus consecuencias y efectos, se deben a una arquitectura de límite y control del poder. ${ }^{35}$

dad a las máximas libertarias. Sobre los modelos, la tesis doctoral inédita, Machado Pelloni, Fernando M., Desobediencia \& delito, op. cit., e ineludible, Mantovani, Ferrando, Diritto Penale. Parte Generale, Cedam, Padova, 2013, p. XXXIV.

${ }^{34}$ En la esfera penal o bien en constelación de derechos constitucionales o convencionales, de acuerdo a Rozo Acuña, E., Le garanzie costituzionali nel diritto pubblico dell'America Latina, Giappichelli, Torino, 2006, p. 28.

$35 \mathrm{El}$ tema, en efecto, abarca una constelación de intereses que no son propiedad exclusiva del derecho, ni lógicamente excluyentes de otras especialidades, todo aunque aquellas lo toquen e, incluso, lo afecten. Para expresarlo prontamente, participa la sociología que con sus herramientas analiza la cooperación y la conflictividad en la comunidad y sus acciones cuanto canal de comunicación, para identificarla y hasta para distinguir su regularidad de lo que deja de caracterizarla. La enorme tolerancia religiosa, exemplo docit, existente en países bajos y escandinavos, en la que no hay empleo de la temática con fines políticos, ni alcanzaría relevancia alguna, no se compara con la que podría perderse en los Estados Unidos, si algunas de las que pueden 
dominar persiguieran imponerse; en un ámbito la sociedad es homogénea frente a la cuestión mientras que en otro es muy diversa; Greenawalt, Kent, Private Consciences and Public Reasons, Oxford U. Press, Oxford, 1995, p. 130. También incursiona la antropología, que reflexiona sobre el ser humano, acerca de sus inicios y de su fin, como la pertenencia a un grupo o sector y la correspondencia de éste con la humanidad; sintéticamente, no es igual la concentración del pensamiento sobre la persona en clave individual, a que aquél lo ignore por completo o que se intente un tertium comparationis. Al decir de Gustav Radbruch, 1789 fue de concepción individualista que entronizó la libertad acaso como una única obligación (negativa) del Estado; al que le es antitética por la idea abusiva del derecho por el ser humano, una que la niega en el marco de una contención, control o subordinación absoluto de aquél;,,Einfübrung in die Rechtswissenschaft 1” en Rechtsphilosophie I (Hrsg. Kaufmann, Arthur), Müller, Heidelberg, 1987, p. 112. Una elaboración sintética ha sido ofrecida por Häberle, para quien la revolución ha sido - iy es!- un positivo punto de partida, sin el cual no existirían críticos que han contribuido a superar su faltante, los que en el arco de su proyección social, por otra, podían rastrearse: así la igualdad o el preámbulo para los "deberes" sociales; Häberle, Peter, Libertad, igualdad, fraternidad. 1789 como historia, actualidad y futuro del Estado constitucional (1789 als Teil der Geschichte, Gegenwart und Zukunft des Verfassungsstaates trad. Gutiérrez Gutiérrez, I.), Trotta, Madrid, 1998, p. 52. Una exposición del plano literario a la realidad acaso pueda aclarar el asunto. Es útil recordar el desprecio hacia la migración, subyacente a un sector del pueblo galo, representado perfectamente en la ficción por Michel Houellebecq, Las particulas elementales (trad. Encarna Castejón), Anagrama, Barcelona, 1999; por la realidad, "First french poll racism" en $B B C$ News, http://news.bbc.co.uk/2/hi/europe/6317799.stm (última consulta, noviembre 28 de 2013). Por eso a nadie podía sorprender la violencia desatada en los suburbios de las más importantes ciudades de Francia a partir de la muerte de unos jóvenes en octubre 27 de 2005. En ese momento, ante un estallido de violencia urbana, el gobierno francés reaccionó con prohibiciones al derecho de reunión, que es lo único que ha sido efectivo de su batería de medidas -sistema de denuncia anónima contra la discriminación, mayor acceso al empleo- que no lograra ninguna integración desde fuera, porque no queda nada desde adentro, porque no hay algo positivo con que tentar la libertad del que está fuera de todo. Se recomienda el análisis de Braudillard, Jean, "The pyres of autum", en New Left Review 37 jan-feb 2006, London, p. 5 ss. Ya en el campo de la abstracción, un proyectista reconocido en la historia de los códigos propuestos que no pudieron suplir al de Moreno (h.), señalaba -con razón- que la regulación de la coacción trasunta todo orden político social; el religioso tiene hechos punibles pe- 
Sin importar la vestimenta con la que se la quiera presentar. ${ }^{36}$ En tal sentido vale colacionar la posición del Tribunal Constitucional español, de plena aplicación frente a conductas policiales sin sospecha razonable y que tachó como una privación ilegal de la libertad el exceso temporal de una limitación bajo detención o arresto, sea por alcanzar el máximo previsto del tiempo legal (violación absoluta), o porque ya se habian despejado dudas o bien ya se habian practicado las gestiones que afectaran la autonomía del interesado en pos del interés público, incluso sin traspasarse el tope de retención o demora (violación relativa), puesto que se persigue la menor demora que sea posible. ${ }^{37}$

riféricos a la cuestión, como el oligárquico es opresivo e inhumano, como el comunista que lucha por los trabajadores. El democrático, entre tantos, ampara derechos y garantías. Remito a Peco, José, "El derecho penal y el Estado”, LL. 1-92. Así la situación, que se pasa las más de las veces por alto, ingresar en la seguridad e intentar -como fuere- ocuparla, hace a una labor que no concluye en un hectárea del mundo legal; al contrario, su extensión es vasta y geográficamente, podría explicársela como contenedora de todos los terrenos y de todos los climas que se conocen. Se dan cita, como se sostiene aquí y se reitera, la esfera iusfundamentalista, si así llamamos a los derechos fundamentales inalienables, la constitucional que recoge aquella y le imprime, a su vez, su propio sello; y la penal que reglamenta, bajo la influencia de las anteriores, la trascendencia de la libertad y sus subsidiarias, una de las cuales resulta la dimensión contravencional.

${ }^{36}$ Los alemanes llaman derecho penal (Strafrecht) al que toca a los hechos punibles de orden personal y derecho penal secundario (Nebenstrafrecht) al que involucra delitos impersonales, lo cual es dogmáticamente bastante objetable: siempre toca a los seres humanos. Ambos participan de los presupuestos limitadores de la coacción estatal. Digamos rápidamente, junto a Vasalli, que cualquier infracción ajena a esa clasificación -contravención por caso- y en la medida que implique consecuencias sobre la libertad, no deja de participar de las bases de aquellos, salvo darle espacio a un pretexto para volver punibles a las personas ante delictum. Véase, "I diritti dell'uomo dinanzi alla giustizia penale”, en Giuliano Vasalli ( $a$ cura di Francesco Palazzo), Laterza, RomaBari, 2010, p. 157ss. La vigilancia debe ser grande sin que valga mucho en nombre de que se limite la libertad; Fairén Guillén, Víctor, La identificación de personas desconocidas (comentario al art. 20 de la ley de protección de la seguridad ciudadana), Civitas, Madrid, 1992, p. 39.

37 Cfr. Gómez Corona, Esperanza, "La inadmisión del hábeas corpus en la jurisprudencia constitucional. La sentencia 165/07 de 2 de julio”, en La Toga, Colegio de Abogados de Sevilla, N 167, febrero 2008, p. 20. 
Ello debe influenciar el comportamiento de agentes de seguridad, para discriminar, en el común escenario de identificaciones o averiguaciones sobre tal o cual sujeto, o por denuncias en las que deberán separar hechos punibles de contravenciones o faltas, y así medir la intensidad y cantidad de la restricción: ahí debe tenderse el puente entre un área racional de la función de administración, con otra tan esencial como lo es el control a ella. Sin ese análisis, la solución los encerrará en el callejón sin salida de la inconstitucionalidad o la anticonvencionalidad: el acceso a la jurisdicción es un factor vital en el refuerzo con el que se cobija a la autonomía, cuando se denuncia -sea el interesado o terceros si el anterior de facto no puede- una explícita lesión a ella, por eso la conducción obligada ante el juez. ${ }^{38}$ Tanto más si acaso no se trata de sospechosos, por cuanto no se aproximan a una norma prescriptiva, taxativa y cerrada mandada por ningún legislador: aquí ya es un estadío anterior a la intervención restauradora y nos concentramos en la tutela anticipada o preventiva. ${ }^{39}$

${ }^{38}$ La lógica deriva de que el presupuesto de la privación de libertad no fue ordenada por un juez; cfr. Gómez Corona, Esperanza, "La inadmisión del hábeas corpus en la jurisprudencia constitucional...”, op. cit., p. 21 con cita de STC 66/1996.

39 En tal caso opera el hábeas corpus resuelto en la ciudad de Bahía Blanca, por el que personal de la Prefectura Naval Argentina barrió de las calles, sin sospecha razonable en orden a un delito y entonces con afectación al nulla poena, nullum crimen sine lege, a individuos dedicados a cuidar automóviles o que se ofrecen para limpiar los vidrios entre el tráfico (también conocidos -y denostados- como "trapitos"). La intervención estatal, como tiene que ser, debe contar con un presupuesto positivo, como lo es un delito o contravención; in re "Hábeas corpus colectivo y preventivo presentado por la Sra. Defensora Dra. María Graciela Cortázar”, octubre 15 de 2013. Ello no signfica que no pueda haber un marco regulatorio, como en cualquier actividad, o que, como cualquier variable ontológica, se cometa un hecho punible y su autor viva o sobreviva en base a aquella, o que la use como enmascaramiento; en tal sentido, no se entiende "la contribución" de un tribunal al debate de un asunto tan claro, por llevar al conocimiento de la legislatura porteña una absolución de quien, según el fiscal del juicio, no había cometido ningún crimen. De hecho, al ir más allá del pedido liberatorio del titular de la acción y pasar a rastros de la etapa oral, dieron cuenta que, sin perjuicio de su competencia como límite de la jurisdicción, en realidad el acusado podría haber hostigado en clave del art. 52 del código contravencional de 
Como ha sido presentada, la garantía del hábeas corpus caracterológica al Estado democrático, está obligada como tal a indagar sobre las condiciones generales de la privación de libertad en términos constitucionales y convencionales (i) y, más precisamente, a verificar los presupuestos especiales en las formas que rodean a la restricción para que sea legal (ii) y en la sustancia como presupuesto de habilitación (iii). ${ }^{40}$

En el conjunto generalista (i) se nos presenta una poderosa arma para repeler e indirectamente, por su alto y veloz impacto, prevenir la tortura, los tratos crueles, inhumanos y degradantes. ${ }^{41}$ En otras

la capital, a quien por no aceptar su ofrecimiento de limpieza de cristales, pasó a golpear la rueda del rodado o la puerta de la conductora e insultar al hijo de aquella; cfr. c. 3657 TOC $\mathrm{N}^{\circ} 20$-presidente Luis Niño, vocales Pablo Laufer y Patricia Mallo- in re "A.A. s/extorsión en grado de tentativa", rta. 18-11-2011. Es decir, cabe la posibilidad de que pueda perturbar o fastidiar el ánimo de un automovilista y con ella homologar una actuación de personal policial (y si la idea fue ideológica por la desregulación de la tarea informal, pareciera, se insiste, desde la decisión judicial, que se alimenta fuera de prudentia iuris, la solución opuesta).

40 Esta idea conceptual subyace al hábeas corpus colombiano, lo que resultó un cambio trascendental a su reglamentación histórica; cfr. Patiño González, María Cristina, "Análisis jurídico de la ley Estatutaria 1095 de 2006 de Hábeas Corpus”, en Estudios Socio-Jurídicos, 8-2, Bogotá, 2006, p. 125.

${ }^{41} \mathrm{El}$ año 2013 se cumple el bicentenario de la proscripción de procedimientos reñidos con la dignidad humana, a instancias de la Asamblea del año 1813. En ese marco se ha llevado a cabo una campaña contra la tortura, los tratos crueles, inhumanos y degradantes, del que participó el ministerio público de la defensa federal, en conjunto con otras instituciones y personas en ejercicio de la función pública y otros que no. Se llevaron a cabo conferencias, jornadas, se recorrieron miles de kilómetros, se ocuparon decenas de hoteles y se invirtieron cientos de horas para mantener intacta la prohibición en cuestión. A pesar de ello, consideramos errado el cálculo con la cruzada: debemos presuponer que los sistemas judiciales locales y todos los ambientes asociados con lo académico conocen y adhieren a la doctrina que hace parte de nuestra historia constitucional, lo que en cualquier caso se vuelve imperativo es volver a instruir o profundizar la materia en los sectores de violencia institucional, en cada academia policial y penitenciaria local de la federación, con cada oficial jerárquico y con sus principales subordinados, puesto que la problemática no está en la mesa entre distintas personalidades que distinguen teóricamente lo correcto de cuanto no lo está, sino debajo de ella, por eso 
expediciones hemos destacado la relación existente entre privaciones de libertad, reverso de detenciones sin sospecha razonable o sin hecho -no importa el nomen iuris- con subsunción legal que imputar, a lo que debe agregarse con sustracción de nuestra garantía para prosperar. ${ }^{42}$ De ahí que su presencia, como centinela, se nos presenta como el (mejor porque es último) mecanismo ad-hoc para velar por la supremacía moral estatal en su actuación por la seguridad pública, o sea de conformidad con los mandamientos convencionales, constitucionales y, cuando corresponda - porque algunas veces no hay adecuación a los recién nombrados- a los infraconstitucionales también. Aunque no se haga expresa mención, no hay duda alguna que el art. 46 de la ley 26.827 que faculta la intervención judicial para salvaguardar la integridad física de un ser humano víctima de la violencia institucional, alude al hábeas corpus y lo encuentra como su mejor aliado en tal cometido. ${ }^{43}$

ahí acierta la ley 26.827 que crea el sistema nacional para la prevención, cuyo art. $4^{\circ}$ define, para el objeto de la reglamentación, el predicado de lugar de detención. Se puede objetar que ella incluyó la difusión en los niveles medios de la educación. Ahora, tampoco ello protege a la juventud de actos que rebajan la autoridad moral estatal por la fuerza antijurídica de sus recursos humanos, cuadros que corresponde formar mejor y reformar también.

Véase por ejemplo la solución del hábeas corpus por el que la Cámara Federal de Apelaciones de Mendoza ordena la internación de una persona en un centro de salud para poder recibir atención médica y que la custodia para ella fuere de un personal de otra fuerza distinta de la penitenciaría de la provincia de San Juan; c. N FMZ 17925/2013, JF N ${ }^{\circ} 2$ Sec. $N^{\circ}$ 5. Si el conflicto subsistiera por incumplimiento de la decisión judicial del superior por el inferior, no se trata de educarle, sino de denunciarle. Para un análisis sobre el tema, Machado Pelloni, Fernando M. "Argumentos contra la tortura, los tratos crueles, inhumanos y degradantes", en Estudios Constitucionales, Año 8, N 1, U. de Talca, 2010, pp. 137-168.

${ }^{42}$ Pej. Machado Pelloni, Fernando M., "Hábeas Corpus: 797-3", op. cit. y "Argumentos contra la tortura...", op. cit.

$43 \mathrm{El}$ art. 46 dentro del Título $\mathrm{V}$ de la ley 26.827 -sancionada en noviembre 28 de 2012, promulgada en enero 7 de 2013-, en el agrupado de estándares para el funcionamiento del sistema nacional de prevención de la tortura, dice: "De la intervención judicial- De verificarse supuestos de tortura, tratos o penas crueles, inhumanos o degradantes, aun en el caso de no contar con el consentimiento del damnificado, deberán instarse todas las acciones judiciales que 
Otro tanto cabe para la desaparición forzada de personas, de pleno interés, desde nuestro parecer, para el tema. ${ }^{44}$ En rigor, la existencia teórica ex ante de una instancia para impedir un abuso o restaurar un quiebre a la vinculación con la ley ex post, ante la imposición de una

resulten necesarias para salvaguardar su integridad”. Sobre la garantía como aliada contra la tortura, de acuerdo, Patiño González, María Cristina, "Análisis jurídico de la ley Estatutaria 1095 de 2006 de Hábeas Corpus”, op. cit., p. 127.

${ }^{44}$ La Convención Interamericana sobre Desaparición Forzada de Personas es uno de los tratados de derecho internacional de los derechos humanos que, con jerarquía constitucional, fue entronizado a la máxima posición normativa ex post a la Constitución reformada en el año 1994, según el propio mecanismo allí fijado; art. 75.22 CN, ley 24.820 (BO. 29-5-1997) en relación a la 24.556 (BO. 18-10-1995). A su vez, Argentina dió con la aprobación de la Convención Internacional sobre Desaparición Forzada de Personas de Naciones Unidas por la ley 26.298. Ambos instrumentos (el primero asociado a hard-law, el segundo a sof-law) plantean una analogía procedimental en la definición de la desaparición forzada contra la que quieren luchar, de gran estímulo para prestar atención ante demandas por vía de la garantía del hábeas corpus: uno señala como desaparición forzada cualquier privación y otro elige enunciar las más conocidas, imputables al obrar estatal y sin eco en sus mecanismos de protección, lo que debería llevar a reconsiderar hábitos de la administración y también de la función de control jurisdiccional. Las dos chocan contra la política criminal de facto.

\begin{tabular}{|c|c|}
\hline Convención Interamericana (OEA) & Convención Internacional (ONU) \\
\hline $\begin{array}{l}\text { II.- Para los efectos de la presente } \\
\text { Convención, se considera desaparición } \\
\text { forzada la privación de la libertad a una } \\
\text { o más personas, cualquiera que fuere } \\
\text { su forma, cometida por agentes del } \\
\text { Estado o por personas o grupos de per- } \\
\text { sonas que actúen con la autorización, } \\
\text { el apoyo o la aquiescencia del Estado, } \\
\text { seguida de la falta de información } \\
\text { o de la negativa a reconocer dicha } \\
\text { privación de libertad o de informar } \\
\text { sobre el paradero de la persona, con } \\
\text { lo cual se impide el ejercicio de los re- } \\
\text { cursos legales y de las garantías pro- } \\
\text { cesales pertinentes. (destacado nuestro) }\end{array}$ & $\begin{array}{l}\text { 2.- A los efectos de la presente } \\
\text { Convención, se entenderá por "desa- } \\
\text { parición forzada" el arresto, la deten- } \\
\text { ción, el secuestro o cualquier otra } \\
\text { forma de privación de libertad que } \\
\text { sean obra de agentes del Estado o por } \\
\text { personas o grupos de personas que } \\
\text { actúan con la autorización, el apoyo } \\
\text { o la aquiescencia del Estado, segui- } \\
\text { da de la negativa a reconocer dicha } \\
\text { privación de libertad o del oculta- } \\
\text { miento de la suerte o el paradero de } \\
\text { la persona desaparecida, sustrayén- } \\
\text { dola a la protección de la ley. (desta- } \\
\text { cado nuestro) }\end{array}$ \\
\hline
\end{tabular}


política criminal de facto - por identificación, por contravenciones que no admiten cautelares subjetivas o faltas administrativas- tiene competencia práctica para, en principio, adoptar reglas a recoger por la función legislativa e incluso mejorarlas o ratificarlas (en la medida que ya existan): en suma, para identificar tiene que existir una marca horaria que ponga fin a la merma en la libertad, como así también y por tratarse de un despliegue de la administración, fuera de un proceso judicial en mar-

XI.- Toda persona privada de libertad debe ser mantenida en lugares de detención oficialmente reconocidos y presentada sin demora, conforme a la legislación interna respectiva, a la autoridad judicial competente.Los Estados Partes establecerán y mantendrán registros oficiales actualizados sobre sus detenidos y, conforme a su legislación interna, los pondrán a disposición de los familiares, jueces, abogados, cualquier persona con interés legitimo y otras autoridades. (destacado nuestro)

XIII.- Para los efectos de la presente Convención, el trámite de las peticiones o comunicaciones presentadas ante la Comisión Interamericana de Derechos Humanos en que se alegue la desaparición forzada de personas estará sujeto a los procedimientos establecidos en la Convención Americana sobre Derechos Humanos, y en los Estatutos y Reglamentos de la Comisión y de la Corte Interamericana de Derechos Humanos, incluso las normas relativas a medidas cautelares. (destacado nuestro).
17.1. Nadie será detenido en secreto.

17.2. Sin perjuicio de otras obligaciones internacionales del Estado Parte en materia de privación de libertad, cada Estado Parte, en su legislación:

a) Establecerá las condiciones bajo las cuales pueden impartirse las órdenes de privación de libertad;

b) Determinará las autoridades que estén facultadas para ordenar privaciones de libertad;

c) Garantizará que toda persona privada de libertad sea mantenida únicamente en lugares de privación de libertad oficialmente reconocidos y controlados;

d) Garantizará que toda persona privada de libertad sea autorizada a comunicarse con su familia, un abogado o cualquier otra persona de su elección y a recibir su visita, con la sola reserva de las condiciones establecidas por la ley, y en el caso de un extranjero, a comunicarse con sus autoridades consulares, de conformidad con el derecho internacional aplicable;

e) Garantizará el acceso de toda autoridad e institución competentes y facultadas por la ley a los lugares de privación de libertad, si es necesario con la autorización previa de una autoridad judicial; 
cha, debe de oficio darse inmediata comunicación a un juez. ${ }^{45}$ Una buena técnica para prevenirse, siempre nos regresa al control del poder, por lo que si nos damos con él, subsiste un mecanismo garantista ad hoc que nos allana el sendero.

En los ámbitos más específicos (ii y iii), los aportes tienen como es lógico más notas distintivas, dado que más allá de la existencia de un marco de legalidad, probablemente los desafíos de la tutela de la

\begin{tabular}{|l|l|}
\hline \hline & $\begin{array}{l}\text { f) Garantizará en cualquier cir- } \\
\text { cunstancia a toda persona privada } \\
\text { de libertad y, en caso de sospecha de } \\
\text { desaparición forzada, por encontrarse } \\
\text { la persona privada de libertad en la } \\
\text { incapacidad de ejercer este derecho, a } \\
\text { toda persona con un interés legítimo, } \\
\text { por ejemplo los allegados de la persona } \\
\text { privada de libertad, su representante o } \\
\text { abogado, el derecho a interponer un } \\
\text { recurso ante un tribunal para que éste } \\
\text { determine sin demora la legalidad de } \\
\text { la privación de libertad y ordene la } \\
\text { liberación si dicha privación de liber- } \\
\text { tad fuera ilegal. (destacado nuestro) }\end{array}$ \\
\hline
\end{tabular}

45 No se discute la tarea dualista que compete a las fuerzas de seguridad: a la par de reprimir hechos punibles, también tienen que prevenirlos; no obstante ello, habrá que separar -mejor- a los sospechosos por un delito de los que lo sean por contravención o falta en la injerencia sobre la libertad. Esta racionalidad en las alternativas se corresponden con las derecho alemán -art. 163c StPO-, Kindhäuser, Urs, Strafprozessrecht, Nomos, Baden-Baden, 2006, p. 57 ss, 81ss, respectivamente para la misión policial y la tarea de interceptación de sospechosos e identificación de no sospechosos; análogo en Colombia, cfr. Patiño González, María Cristina, "Análisis jurídico de la ley Estatutaria 1095 de 2006 de Hábeas Corpus”, op. cit., p. 135. En la Ciudad de Buenos Aires -aunque también pudiera ocupar su lugar Córdoba (capital)- se da un fenómeno particular. Para contener el imperio normativo de lo fáctico del personal policial, el constituyente prohibió el dictado de cautelares subjetivas bajo imputaciones por contravenciones -art. 13.11 de la Ley Mayor-; sin embargo, subsisten los traslados de personas bajo una constelación de pretextos y por largas horas, situación que nos devuelve a la violación absoluta 0 relativa de la autonomía, es decir al alcance de lo que la judicatura local (no) quiera ver o analizar (ut-supra, nota 40 e ut-infra, nota 53). 
libertad se deban a normas jurídicas puntuales. ${ }^{46}$ Desde la observación de (presuntos) problemas de seguridad pública, ${ }^{47}$ se dan (absurdas) soluciones con observación de dos fenómenos: en la emergencia (muchas veces de ideas) se consagran excepciones normativas, o se hace abandono de los fundamentos que limitan u obligan a la intervención penal. ${ }^{48}$ Cualquier disposición que cumpla con el mecanismo constitucional formal o procedimental para sancionar una ley pero que atente contra la autonomía material, no sobrevive al hábeas corpus -art. $43 \mathrm{CN}-$ : una interpretación que se desentienda de la sustancia, por el privilegio de lo ritual, homologa una politica criminal impropia del Estado democrático de derecho. ${ }^{49}$ Ello es determinante para proponer una revisión al análisis

${ }^{46}$ Esta descripción engendra un peligro que conviene desactivar: el hábeas corpus aunque se trabe en lucha contra situaciones arbitrarias, toma la legalidad en un amplio sentido, sea por actos fuera de ella, contra ella o progresivamente apartándose de ella; cfr. Montón Redondo, Martín, "E1 derecho de hábeas corpus" en Derecho Procesal, U. de Extremadura, 1989, p. 176.

47 Es bastante asombroso advertir una constante concentración de la política en los resultados -el delito-, antes que en los antecedentes -factores que inciden en él-. De nuevo, remitimos a Mantovani, Ferrando, Il problema della criminalitá, op. cit., p. 93ss; véase además Rock, Paul, "Sociological theories of crime", en The Oxford Handbook of Criminology, ed. Maguire, M.-Morgan, R.-Reiner, R., Oxford U. Press, NYC, 2007, p. 7ss.

48 Se hace inclusión de categorías sospechosas como nacionalidad, religión, etc., pej. Patiño González, María Cristina, "Análisis jurídico de la ley Estatutaria 1095 de 2006 de Hábeas Corpus”, op. cit., p. 128; como otras irracionales, pej. I-72427 "Centro de Estudios Legales y Sociales y otros c/prov. de Buenos Aires s/inconst. Ley 14.434” SCBA, 26-02-2013, donde el tribunal supremo bonaerense suspendió la limitación del art. 171 del código de procedimientos local, que restringía la libertad por determinados delitos, una "categoría abstracta de lo no excarcelable" (jueces Lazzari, Negri y Genoud). Esto ha ocurrido en otros derechos comparados, en especial con la "guerra contra el terrorismo", que alteró el hábeas corpus como protector de la libertad en los Estados Unidos. Por más de diez años se sucedieron decisiones ejecutivas y leyes del congreso federal de aquél país, a lo que hay que sumar que si bien alternó rechazos con admisiones de petitorios, cuando la Suprema Corte cuestionó la normativa que sustraía el debido proceso de los acusados a nivel constitucional o desconocía el derecho internacional humanitario, la función legislativa no se hizo cargo de la señal de sus fallos. 
con el que se convalida la actuación de la administración en la seguridad que persigue, a través del control migratorio; dado que se condiciona el ejercicio o el recupero de la libertad, perseguido por el hábeas corpus, y resulta ser que la infracción de la reglamentación del ingreso o la permanencia en el país es tratado concretamente como un hecho punible, aunque en definitiva no lo sea. ${ }^{50}$ Se considera esencial que la

Pej, cuando en "Rasul v. Busch" 542 US 466 y "Hamdi v. Rumsfeld" 542 US 507 (2004) se dijo que prisioneros de Guantánamo debían contar con la garantía, se instrumentó un mecanismo ad hoc (Combatant Statute Review Tribunal, CSRT) que nada tiene que ver con aquella; en efecto se creó una comisión para revisar el estatuto de "combatiente irregular" inmediatamente después de la opinión del Tribunal Supremo, y recién después de ello, se podría llegar a la petición tal y como se la conoce. En 2005 se sancionó el estatuto de los detenidos (Detaniee Treatment Act, DTA), prohibió la tortura pero también su garantía: un cheque a la violencia institucional. Inmediatamente el ejecutivo dispuso comisiones militares especiales de juzgamiento (Military Commisions Act, $M C A$ ), descalificado en "Handam $v$. Rumsfeld" 549 US 597 (2006), por carecer de base legislativa y no por ser ad hoc o ex post facto, lo que llevó a que el legislador la homologara. Una vez más, la Suprema Corte declaró que ello interfería con el hàbeas corpus in re "Boumedine v. Bush" 553 US 723 (2008), donde despejó dudas respecto a los fundamentos del proceso legal debido -tribunal imparcial para evaluar si se puede suspender la garantía, si en efecto esta ha sido suspendida y si ella distingue personas a proteger, ciudadanos o no-; Dasgupta, Riddhi, "Boumedine v. Bush and Extraterritorial habeas corpus in wartime", en Hastings Constitutional Law Quaterly 36-3, 2009, p. 425ss. Más análisis, Machado Pelloni, F. "Hábeas corpus: pasado, presente y futuro. Teoría y práctica”, op. Cit; más amplio, Moeckli, Daniel, Human Rigths and non discrimination in the 'War on Terror', Oxford U. Press, Oxford, 2008, que explora los criterios por los cuales se termina por traspasar la prohibición de discriminación arbitraria y demuestra como hay alternativas menos lesivas. Las consecuencias de la selectividad y la excepción son la muerte, como lo expuso el caso del natural de Yemen, Adnan Farhan Abdul Latif en setiembre de 2012, quien atravesó desde 2002, por todas las órdenes ejecutivas y disposiciones legislativas, sin mayor suerte en los tribunales federales de Estados Unidos, que siquiera tuvo una autopsia cuyos resultados podamos conocer. Cfr. editorial, "A Guantanamo death", International Herald Tribune, 17-09-2012, p. 6.

${ }^{50}$ Los ingresos irregulares conllevan expulsión según el art. 37 de la ley 25.871; tampoco una permanencia ilegal abandona el plano administrati- 
expulsión derivada de la contradicción con el régimen de migraciones, con oportunidad de defensa y control para el infractor, sea inmediata y, en un paso previo, retenerle lo mínimo y necesario en tales extremos, en un lugar apropiado que no es la prisión. ${ }^{51}$

vo entre nosotros y ambas elecciones desechan al control migratorio como eje de la intervención penal, de ahí que no puede tolerarse amplias retenciones para una ulterior expulsión. No ocurre así en Alemania. En efecto, cualquiera de estos comportamientos pueden llevar como consecuencia pena de prisión de hasta un año e imposición de multa, en los términos del art. 95.1 de la Aufenthaltsgesetz y posiciona como objetivo primario la estabilización y el control migratorio. Cfr. Gericke, Jan,, AufenthG” en Münchener Kommentar zum Strafgesetzbuch (Lagodny, O.), Beck, München, 2009, p. 73. Lo que aquí se sostuvo se aplica a otros escenarios de la administración.

51 Ahí la crítica contra la postura de rechazo de la Cámara Federal de La Plata in re "LQ., GZY, YY, YBX, ZHF, ZSG, LWP, LXF, ZDQ, CPH y SLF s/hàbeas corpus", Sala I, expte. 6112, rta. 29-3-2012. El Tribunal en cuestión crítica la interposición de presentaciones que demoran la expulsión, cuando en realidad, por la naturaleza, debería acelerar la resolución, para posibilitarla cuanto antes; además pasa sin considerar puntos muy delicados, que debieron haber llevado más estudio. Si es cierto, como se recoge en la resolución, que los accionantes fueron testigos en un proceso por trata de personas, la buena práctica del derecho internacional de los derechos humanos y del derecho penal internacional se orienta hacia la autorización excepcional de permanencia, cuanto menos, hasta la resolución del proceso que los involucra por este hecho punible, como sucede en Alemania. Ello difiere cuando esas circunstancias no parecen darse, según el citado órgano, in re "WXF y LWW s/hábeas corpus" expte. 6207, rta. 3-07-2012, como cuando un ciudadano intenta ingresar sin más con documentación falsa y su expulsión está ordenada e inminente resulta ser. Dicho lo anterior, es atinado convocar la experiencia comparada del derecho español, que tiene iguales o agravados problemas (derivados de Africa, o sea de gente que no tiene que comer o cuya expectativa de vida puede detenerse en 30 años): allí se separa la prohibición en el goce del derecho de libre circulación por quien no se ajusta a la ley migratoria, de la afectación de la libertad y el acceso a la tutela judicial efectiva. Mientras lo primero es razonable, no tiene ese atributo la prohibición de quien quiera poner una situación restrictiva -por obra del control fronterizo- bajo control judicial, por ejemplo, para que una expulsión sea (lo más) inmediata; SSTC 179/2000, Pérez Sola, Nicolás, "Las limitaciones al derecho a la libertad en el ámbito de la ley de extranje- 
Aunque no acaba allí: la deliberada o inconciente renuncia a la necesidad, utilidad y proporcionalidad de la legislación sustantiva ilustra sobre la aparición de escalas punitivas tendientes a anticipar penas por medio de prisiones preventivas, dándonos descripción de los enemigos escogidos por el Estado de Derecho, algo inviable en él. ${ }^{52}$ Es nuestra ingeniería la que, si acaso no están reunidos los extremos que imposibilitan el progreso del juicio penal, debe cuestionar ese perverso enmascaramiento, que no puede aguardar -por irreparable-, ante el daño a la autonomía por una sentencia definitiva..$^{53}$

ría y la operatividad del procedimiento de hábeas corpus”, en Revista de la UNED, 3-2008, Madrid, p. 241. Sobre esto también, Fairén Guillén, Víctor, La identificación de personas desconocidas, op. cit., p. 43.

52 Sobre ello, se alerta que el ex director del departamento de derecho penal y filosofía del derecho de la facultad de drecho de la universidad de Bonn, había señalado que se limitaba a describir como "enemigo" a lo que ya estaba en los ordenamientos estatales, seleccionados conforme las reglas sociales e institucionales existentes y que él no propiciaba un giro en el derecho material, sino más bien una flexibilización de las injerencias en la libertad durante el procedimiento. Cfr. Jakobs, Gunther,„Feindstrafrecht? - Eine Untersuchung zu den Bedingungen von Rechtlichkeit”, Onlinezeitschrift für Höchstrifterliche Rechtsprechung im Strafrecht (HRRS, www.strafrecht. de), 8-9, 2006, s. 289ss. Sobre la enunciación de supuestos, basta la parte especial del CPA y sin pretensión de agotar su enunciado parte de los siguientes ejemplos: art. 139 -descalificado por la Corte Federal, Fallos: 321:3630-; art. 189 bis (2) in fine -desautorizado pero por la Cámara Federal de Casación Penal, in re "Amato, Diego Marcos s/rec. de revisión", Sala I, c. 15.949, reg. 21.199, rta. 12-06-2013-. Es altamente recomendable la respuesta del Prof. Dr. Aponte, Alejandro, Guerra y derecho penal del enemigo. Reflexión crítica sobre el eficientismo penal de enemigo, Ad-Hoc, BsAs., 2008, toda la obra, con particular atención p. 300ss, 350ss; también el repaso por los bases y el sentido de humanidad en el derecho penal en sentido historiográfico, Radbruch, G.,Das Strafrecht der Zauberflöte”, en Kulturphilosophie und kulturhistorische Schriften (Hrgs. Spendel, G.), C. F. Müller, Heidelberg, 2002, p. 283ss.

53 Si la autoridad obra de mala fe, caprichosamente o por un mal o colateral propósito, el hábeas corpus puede progresar; Gans, J.-Henning, T.-Hunter, J.-Warner, K., Criminal Process and Human Rights, The Federation Press, Sydney, 2011, p. 162. 


\section{IV.- CierRe: hábeas Corpus como garantía de LA Dignidad}

Existe consenso en admitir que el objeto de protección cuando se habla de derechos fundamentales, por ejemplo a través de los procesos constitucionales, es el contenido constitucional (convencionalmente alimentado o retroalimentado) de cada derecho. La protección de aquél es la garantía de su incolumnidad: todo derecho humano tiene un contenido constitucional que vincula y exige ser respetado. En este sentido en la doctrina se habla de la "garantía del contenido esencial" de los derecho fundamentales para hacer referencia al contenido constitucional vinculante y exigible que trae consigo cada derecho fundamental. El "contenido constitucional" o "contenido esencial" de cada derecho fundamental así entendido, será vinculante no solo con respecto al legislador, sino también respecto de la función ejecutiva y de la judicial, como órganos del poder público e incluso de particulares.

Si bien en el último punto hay consenso, no ocurre lo mismo cuando se pretende establecer cuál es, o cómo determinar el contenido constitucional de un derecho fundamental concreto. Por la argumentación precedente, una medida de injerencia que afecte el derecho fundamental de libertad, como ser una restricción procesal o procedimental - penal o administrativa- en acción directa o por un enmascaramiento sustantivo, que sea desproporcionada e irracional, lo que es señalarla como manifiestamente injusta en la violación al debido proceso en su dimensión material, debe atenderse por vía del hábeas corpus. ${ }^{54}$ Según nuestro parecer, ello no solo ocurre cuando se afectan algunos de los presupuestos formales, sino también cuando no se observa dignidad en la intervención penal, es decir un criterio objetivable a través de los principios de necesidad, idoneidad, razonabilidad y proporcionalidad. Se trata de una resistencia opuesta ante un descomunal desconocimiento de los fundamentos que cimientan el Estado de Derecho y los que orientan a su

${ }^{54}$ Lo injusto puede tratarse de un error por inexistencia de antecedente lógico para la consecuencia restrictiva, por insuficiencia de prueba, porque la longitud temporal va mucho más allá de las necesidades del interés, porque la decisión no está bien constituida, entre otros casos; Gans, J.-Henning, T.-Hunter, J.-Warner, K., Criminal Process and Human Rights, op. cit., p. 161 y sus citas. 
política criminal. También de una ambiciosa y no menos pretensiosa defensa frente a la arbitrariedad reinante en lugares ajenos al común de la sociedad (aunque no de los jueces que pertenecen a ella). ${ }^{55}$

Armado de los principios enunciados, el hábeas corpus diagrama un mundo posibilista con la finalidad de ayudar a establecer si una intervención sobre el derecho fundamental de libertad dictada con fundamento jurídico y, en general, opuesto, ocasiona o no una lesión o merma proporcionada a la autonomía restringida y ello con la pretensión de decidir si se dé o no la cobertura constitucional y convencional aclamada. En otras palabras, está llamado a determinar la constitucionalidad y convencionalidad de toda medida -legislativa, ${ }^{56}$ ejecutiva $^{57} \mathrm{o}$

55 Debe atenderse, como desde hace años correspondería al servicio penitenciario federal, la violación de la dignidad en lo que hace a sus traslados, por razones de trámite de los procesos. Cabe plena aplicación aquí de la violación relativa en lo que toca al espacio temporal que demanda un trayecto de una prisión a un juzgado o tribunal, ut-supra III, nota 37. Aunque por agravamiento de una detención legal. Es un trato cruel, inhumano y degradante; cuando no directamente una tortura; que la solicitud judicial asuma, en la práctica, que se lo despierte al interno a la medianoche y que llegue agotado, por falta de descanso, a la sede; doctrina app. 5310/71 CEDH, "Ireland v. United Kingdom", rta. 18-01-1978, remitimos a Machado Pelloni, Fernando M., "Argumentos contra la tortura, los tratos crueles, inhumanos y degradantes”, op. cit. En el caso andaluz, se ha cuestionado la dilación con la que se efectuaba mayormente el traslado de los detenidos a los órganos jurisdiccionales, pues debía hacerse en el lapso más breve, sin dilación o demora; SSTC 199/1987, 224/1998, 288/2000 citadas por Grupo 17 de marzo-Sociedad Andaluza de Juristas, "El hábeas corpus y la situación de los detenidos en Sevilla capital jes constitucional la práctica institucionalizada de una sola conducción de detenidos al día?”, La Toga, Colegio de Abogados de Sevilla, $N^{\circ} 163,2007$, p. 48ss. Este modalidad sería hábeas corpus correctivo-preventivo de un humano descanso; Machado Pelloni, F. M. (con colaboración de Bouyssou, N. I.), "El hábeas corpus”, en Tratado de Derecho Procesal Constitucional T.I, Manili, Pablo-director, La Ley, 2010, p. 662ss.

${ }_{56}$ Notas supra 45, 48 y 52.

57 Clara expresión de ello ha sido lo obrado por la Cámara Federal de Apelaciones de Mar del Plata, en el hábeas corpus frente a la Resolución No 85/2013 del Ministerio de Defensa de la República, que en su art. $1^{\circ}$ prohíbe la internación o asistencia en hospitales militares o dependientes de las fuerzas arma- 
judicial ${ }^{58}$ - que la afecte. Mientras resuelve el conflicto, nos recuerda que en el sistema de medios y fines, el poder está a mitad de camino, sirve a la coacción si lo hace también con el objeto jurídico, que es el ideal libertario con justicia. ${ }^{59}$

das, a quienes han sido condenados o están procesados con prisión preventiva, que tengan o hayan tenido estado militar, lo que alcanzaba a la totalidad según el art. $2^{\circ}$. Ello originado en la fuga de dos personas de un establecimiento sanitario castrense. En el caso "C" -c. 2/219, reg. 641, rta. 15-08-2013, jueces Tazza y Ferro- el tribunal de referencia rechazó la apelación estatal, y en consecuencia confirmó lo que dispusiera el a quo, que ordenó continuar el tratamiento de los afiliados a la obra social y en el establecimiento hospitalario perteneciente al brazo armado del Estado. Tal decisión se hacía eco del estado de salud y del tratamiento, que desaconsejaba la abrupta interrupción., más aún, si se contaban chequeos tras intervenciones quirúrgicas recientes. Quizás en el futuro podrían asegurarse las asistencias en otros centros de salud.

Es destacable la solución del hábeas corpus por el Juzgado de Garantías $\mathrm{N}^{\circ}$ 1 del departamento de Moreno-Gral. Rodríguez, en el proceso $\mathrm{N}^{\circ} 7192$ "Pereyra Manuel Federico s/habeas corpus", rta. 5-11-2013. El nombrado tenía dictada una prisión preventiva por robo calificado por el uso de arma de fuego, utilizada en forma impropia y también por haberse cometido en poblado y en banda, arts. $45,166.2$ párrafos $1^{\circ}$ y $2^{\circ}, 167.2 \mathrm{CPA}$., con disposición conjunta con la justicia federal -Juzgado en lo Criminal y Correccional Federal $\mathrm{N}^{\circ} 1$ de capital, al momento de resolver Tribunal Oral en lo Criminal Federal $\mathrm{N}^{\circ} 1$ - por infracción a la ley federal 23.737. El interesado en la acción - porque la intentó un abogado vinculado con organizaciones ligadas a la defensa de los derechos humanos- estuvo internado en Olmos y con pedido para ir al centro sanitario de la unidad federal sita en Ezeiza, con graves lesiones por arma de fuego, lo que no fue posible por cupo. Había perdido el bazo, con sondas, una que perdió y derivó en una infección que motivó el traslado a un hospital extramuros, tenía que recibir medidas de higiene para preservar su salud que no eran provistas por el servicio penitenciario bonaerense, cuyo servicio de sanidad no respondía por diversas razones, como resolver el tratamiento del interno. Entonces el magistrado local, con cita de Fallos: 318:2002 y 332:2842 y las complicaciones derivadas de su salud, consideró que la medida cautelar debia modificarse a prisión domiciliaria, la que no hizo efectiva sino hasta que la otra jurisdicción también acompañara el criterio (a la que parecía no tener alternativa constitucional y convencional alguna).

59 No pasa, a pesar de los años, la actualidad de la relación elaborada por el gran iusfilósofo y penalista, Mayer, Max Ernst, Filosofía del Derecho (Rechtsphilosophie, trad Legaz Lacambra, L.), Labor, Barcelona, 1937, p. 171. 
Dentro del marco teórico en el que cobra vida la dignidad, encontramos las aplicaciones prácticas del proceso de hábeas corpus; sin pasar por alto que el proceso constitucional no tiene por objeto, emitir pronunciamiento alguno sobre temas de fondo en un proceso judicial, habida cuenta de su "cognición limitada", no hace menos que velar porque toda medida restrictiva de la libertad, en sus múltiples variantes, obedezca a criterios de razonabilidad y proporcionalidad, en un marco de legalidad constitucional y convencional. Eso es mucho, aunque quizás en la vida real todavía no sea tanto: del peso de la jurisprudencia se distingue un control más light en la actuación inicial de la administración, de otro que por necesario -no decimos suficiente- es superior en etapas progresivas del juicio penal. Sin embargo, esto último no tiene nada que ver con la garantía y es un problema analíticamente diferente.

\section{COMO CITAR ESTE ARTIGO:}

BOUYSSOU, Norma I.; PELLONI, Fernando M. Machado. Hábeas Corpus: contribuciones a la causa del estado de derecho. Revista Brasileira de Direito Processual Penal, Porto Alegre, vol. 2, n. 1, p. 111 - 143, 2016. http://dx.doi.org/10.22197/rbdpp.v2i1.19 